\title{
Hypovitaminosis D in dogs with spirocercosis
}

C.T. Rosa ${ }^{1}$, DVM, BVScHons

J.P. Schoeman ${ }^{1}$, BVSc, MMedVet(Med), PhD, DSAM, Dip. ECVIM-CA, MRCVS

R.J. Mellanby², BSc, BVMS, PhD, DSAM, Dip. ECVIM-CA, MRCVS

J.L. Berry ${ }^{3}$, BSc, MSc, PhD, MICR, CSci

E Dvir ${ }^{1}$, DVM, BVScHons, MMedVet(Med), PhD, Dip. ECVIM-CA

${ }^{1}$ Department of Companion Animal Clinical Studies, Faculty of Veterinary Science, University of Pretoria, Private Bag X04, Onderstepoort, 0110, Republic of South Africa.

${ }^{2}$ The Royal (Dick) School of Veterinary Studies, Division of Veterinary Clinical Studies, Hospital for Small Animals, Easter Bush Veterinary Centre, The University of Edinburgh, Roslin, Midlothian EH25 9RG, UK.

${ }^{3}$ Vitamin D Research Group, Department of Medicine, Manchester Royal Infirmary, Oxford Road, Manchester ML13 9WL, UK.

Corresponding author: Dr. C.T. Rosa ${ }^{1}$ - chantalrosa5@gmail.com

Running head title: Hypovitaminosis D in spirocercosis.
Abbreviations:
$1 \alpha(\mathrm{OH})_{\text {ase }} \quad 1 \alpha$-hydroxylase
$1,25(\mathrm{OH})_{2} \mathrm{D} \quad 1,25$-dihydroxyvitamin $\mathrm{D}$ or calcitriol
$24(\mathrm{OH})_{\text {ase }} \quad$ 24-hydroxylase
$25(\mathrm{OH})_{\text {ase }} \quad 25$-hydroxylase
25(OH)D 25-hydroxyvitamin D or calcidiol
CBC Complete blood count 


$\begin{array}{ll}\text { CT } & \text { Computed Tomography } \\ \text { DBP } & \text { Vitamin D-binding protein } \\ \text { FGF }_{23} & \text { Fibroblast growth factor } 23 \\ \text { HPLC } & \text { High-performance liquid chromatography } \\ \text { IBD } & \text { Inflammatory bowel disease } \\ \text { ISO } & \text { International Organization for Standarization } \\ \text { RI } & \text { Reference interval } \\ \text { S. lupi } & \text { Spirocerca lupi } \\ \text { VDR } & \text { Vitamin D receptor }\end{array}$

This prospective study was performed at the Onderstepoort Veterinary Academic Hospital, Department of Companion Animal Clinical Studies, Faculty of Veterinary Science, University of Pretoria. The results of this study were presented at the $22^{\text {nd }}$ ECVIM-CA Annual Congress, 2012, Maastricht, The Netherlands.

\begin{abstract}
Background: Canine spirocercosis is characterized by esophageal nodules that can undergo neoplastic transformation. Hypovitaminosis D has been associated with neoplasia formation. We hypothesized that hypovitaminosis $\mathrm{D}$ is present in neoplastic spirocercosis and it could be a risk factor for neoplastic transformation.
\end{abstract}

Objective and animals: To measure and compare vitamin D status, assessed by serum 25hydroxyvitamin D [25(OH)D] concentrations in non-neoplastic (Group A, n=25) and neoplastic (Group B, n=26) spirocercosis dogs and healthy dogs (Group C, n=24). 
Methods: Serum 25(OH)D concentration was measured by high-performance liquid chromatography. Dogs were excluded if less than 1 year-old, had concurrent diseases, received corticosteroids or treated prophylactically for spirocercosis. Spirocercosis dogs' appetite was graded and compared.

Results: Serum 25(OH)D concentrations were significantly different among all groups $(\mathrm{p}<0.001)$. Median 25(OH)D concentrations were significantly lower in the neoplastic group [30.7 nmol/1 (range 14.7-62.2)] compared to the non-neoplastic [52.7 nmol/1 (range 19.1-129.7, $(\mathrm{p}<0.05)]$ and the healthy groups $[74.6 \mathrm{nmol} / 1$ (range 37.4-130.5, $\mathrm{p}<0.005)]$. Median 25(OH)D concentrations were also significantly lower in the non-neoplastic spirocercosis group compared to the healthy one $(\mathrm{p}<0.05)$. No significant differences in appetite scoring were noted between spirocercosis groups $(\mathrm{p}=1.0)$ nor in the median $25(\mathrm{OH}) \mathrm{D}$ concentrations of dogs with normal or abnormal appetite either within the non-neoplastic $(\mathrm{p}=0.125)$ or the neoplastic spirocercosis groups $(\mathrm{p}=0.0869)$

Conclusions and clinical importance: Vitamin D status is lower in dogs with neoplastic spirocercosis compared to the non-neoplastic spirocercosis and healthy dogs. Further studies are warranted to determine the potential use of vitamin D treatment in spirocercosis and to explore its role in the pathogenesis of hypovitaminosis $\mathrm{D}$ in the malignant transformation.

Keywords: Vitamin D; Calcidiol; Dog; Neoplasia.

\section{Introduction}

Canine spirocercosis is caused by the nematode Spirocerca lupi (S. lupi) and characterized by esophageal nodules which can undergo neoplastic transformation ${ }^{1-2}$ and form an osteosarcoma, fibrosarcoma or undifferentiated sarcoma ${ }^{1-4}$. The pathogenesis behind this neoplastic 
transformation remains poorly understood, hence the need for further investigation. Spirocercosis is a good model to study helminth-induced neoplasia and factors associated with neoplastic transformation, based on the presence of two groups of dogs with the same disease, presenting with identical clinical signs differing only by the neoplastic stage of disease progression ${ }^{5}$.

Spirocercosis diagnosis is based on the detection of $S$. lupi eggs on fecal evaluation ${ }^{4}$, pathognomonic thoracic radiographic or computed tomography (CT) findings (spondylitis, esophageal mass and aortic aneurysm $)^{6}$, esophagoscopy ${ }^{6}$, response to therapy and/or histopathology of the nodules ${ }^{5}$. Therefore, in the presence of these characteristic findings spirocercosis diagnosis is relatively easy. Confirmation of concomitant neoplastic transformation, however, is challenging requiring invasive or expensive diagnostic tools. The endoscopic appearance of the nodules ${ }^{3-4}$, poor treatment response, presence of hypertrophic osteopathy $^{6}$, anemia, leukocytosis and hyperglobulinemia ${ }^{6-7}$ have been suggested as indicators of neoplastic transformation, although their sensitivity is poor. Histopathology is the gold standard for definitive diagnosis of neoplastic transformation ${ }^{5}$. However, endoscopic-guided biopsies can capture the necrotic periphery of the nodule, rendering it highly insensitive. In view of the pitfalls surrounding the definitive diagnosis of spirocerca-induced neoplastic transformation, the search for a simple reliable screening test to determine the neoplastic transformation is necessary.

Vitamin D is a secosteroid hormone, well known for its role in calcium regulation. It also plays an important non-calcemic role in the regulation of the immune function, cell proliferation and differentiation, and modulation of gene expression ${ }^{8}$, all of which have been implicated in the development of neoplasia. The extra-skeletal vitamin D functions were discovered when vitamin $\mathrm{D}$ receptors (VDR) were identified in many normal and neoplastic cells ${ }^{9-13}$. Vitamin D 
supplementation has been described in the treatment of veterinary patients with renal ${ }^{14-15}$, metabolic $^{16-17}$ and neoplastic diseases ${ }^{18-20}$.

The anti-neoplastic vitamin D effect relates to its capacity to inhibit cell proliferation and angiogenesis and stimulate cell differentiation and apoptosis ${ }^{21}$, with the activity of 1,25dihydroxyvitamin $\mathrm{D}\left[1,25(\mathrm{OH})_{2} \mathrm{D}\right]$, being far more active in initiating the response than 25 hydroxyvitamin $\mathrm{D}[25(\mathrm{OH}) \mathrm{D}]$. This is initiated and maintained by growth factors that lead to vitamin D activation/inhibition of genomic functions and subsequent formation of transcription factors, inhibiting tumour growth and metastatic disease ${ }^{22}$.

The most common canine source of vitamin D is dietary intake. Once absorbed in the gastrointestinal tract ${ }^{11-12}$, it is transported by the vitamin D-binding protein (DBP) to the liver and other target $\operatorname{sites}^{13}$. In the liver, this biologically inactive form undergoes activation by hydroxylation to $25(\mathrm{OH}) \mathrm{D}$, the major circulating form of vitamin $\mathrm{D}$ and the one most widely used to assess vitamin D status ${ }^{9,11-13}$. Furthermore, in the kidneys, 25(OH)D is converted to $1,25(\mathrm{OH})_{2} \mathrm{D}$, the most biologically active form, by $1 \alpha$-hydroxylase $(1 \alpha(\mathrm{OH}) \text { ase })^{9,11-13}$. Regarding catabolism, fibroblast growth factor $23\left(\mathrm{FGF}_{23}\right)$ production activates the 24-hydroxylase $[(24(\mathrm{OH})$ ase $)]$ and inhibits the $1 \alpha(\mathrm{OH})$ ase activities resulting in reduction of $25(\mathrm{OH}) \mathrm{D}$ and $1,25(\mathrm{OH})_{2} \mathrm{D}$ concentrations ${ }^{11}$. Therefore, vitamin $\mathrm{D}$ intake, liver function, $\mathrm{FGF}_{23}$ and $24(\mathrm{OH})$ ase concentrations influence serum $25(\mathrm{OH}) \mathrm{D}$ concentrations, while serum $1,25(\mathrm{OH})_{2} \mathrm{D}$ concentrations depend on regulating minerals (serum calcium and phosphorus), hormones (parathyroid hormone, serum $25(\mathrm{OH}) \mathrm{D}$ concentrations), kidney and liver function, and on the production of extra-renal tissue enzymes/factors $\left(1 \alpha(\mathrm{OH}) \text { ase, } \mathrm{FGF}_{23} \text { and } 24(\mathrm{OH}) \text { ase }\right)^{9,11-13}$.

There are many studies linking hypovitaminosis D to a higher neoplastic risk in humans ${ }^{9-}$ 10,12,21-22 and some in $\operatorname{dog} \mathrm{s}^{19,23}$. The anti-neoplastic effect of vitamin $\mathrm{D}$ in dogs has also been 
proven $^{18,23-24}$. Therefore, vitamin D may potentially play a role in the spirocerca-induced neoplastic transformation. We hypothesized that hypovitaminosis D is present in spirocercosis and that it may potentially lead to its neoplastic transformation. The objective of this study is to measure and compare serum 25(OH)D concentrations between dogs with non-neoplastic and neoplastic spirocercosis and healthy dogs.

\section{Materials and Methods}

\section{Selection of cases}

Fifty one client-owned dogs diagnosed with canine spirocercosis at the Onderstepoort Veterinary Academic Hospital in South Africa were included in the study with owner consent. Twenty five of these dogs were diagnosed with non-neoplastic spirocercosis (Group A, n=25) and 26 with neoplastic spirocercosis (Group B, n=26). Twenty four healthy dogs were used as a control group (Group C, $n=24$ ). The spirocercosis cases were randomly selected from a total of 119 spirocercosis cases (39 neoplastic and 80 non-neoplastic) that presented to our hospital over a three year period.

Inclusion criteria for all dogs diagnosed with spirocercosis were a complete blood count $(\mathrm{CBC})$, serum biochemistry, urinalysis, fecal analysis, modified centrifugal fecal flotation, thoracic radiographs and/or thoracic computer tomography (CT) and upper-gastrointestinal endoscopy. The differentiation between the non-neoplastic and neoplastic groups was based on macroscopic findings during endoscopy; positive responses to doramectin therapy in suspected non-neoplastic cases with subsequent endoscopic confirmation of clinical cure denoted by absent esophageal nodules post-treatment. The non-neoplastic dogs had a follow-up esophagoscopy performed at days 48 to 56 post-diagnosis and therapy to assess clinical response and cure. If no 
nodules were detected, clinical cure was assumed and prophylactic therapy instituted. If the nodules were still present although smaller or reduced in number, therapy was continued for another 6 weeks and esophagoscopy performed a second time to assure clinical cure.

Neoplastic dogs were diagnosed by thoracic CT with evidence of esophageal mass(es) and compatible lung metastatic lesions; and histopathology of nodules/masses removed either surgically or obtained by endoscopic biopsy or during post-mortem examination. Neoplastic spirocercosis dogs were offered therapy by surgical excision with or without chemotherapy, symptomatic therapy (anti-ulcerative and anti-emetic therapy and/or application of a percutaneous endoscopic gastrotomy feeding tube) or euthanasia followed by a post-mortem and histopathology. Surgery was performed in 1/26 dogs but not followed by chemotherapy, 2/26 dogs were given symptomatic therapy for a total 1-2 months and remaining 23/26 dogs were euthanased within few days post-diagnosis.

In the healthy dogs, anamnesis, $\mathrm{CBC}$, serum biochemistry, urinalysis, fecal analysis, modified centrifugal fecal flotation and thoracic radiographs were performed to rule out canine spirocercosis or any other systemic disease.

Exclusion criteria for all dogs of all groups included dogs less than 1 year of age or with evidences of liver or renal disease based on clinical signs, serum biochemistry, urinalysis, abdominal ultrasound and post-mortem. Dogs with concurrent diseases, treated with medications that could influence vitamin D concentrations (corticosteroids, anticonvulsants, calcium channel blockers, diuretics ${ }^{25}$ during the past month or treated prophylactically for canine spirocercosis in the past 6 months were also excluded. The prophylactic therapy for canine spirocercosis was the only exclusion criterion not considered in the healthy dogs group. 


\section{Appetite scoring}

The appetite of all dogs diagnosed with spirocercosis was scored as normal or abnormal (decreased appetite or total anorexia) based on information obtained from the owners. The type of diet (commercial, home cooked or mixed) was also questioned in all dogs.

The appetite scores were compared between the non-neoplastic and neoplastic spirocercosis groups and then further compared to the serum $25(\mathrm{OH}) \mathrm{D}$ concentrations of each spirocercosis group.

\section{Test method}

Serum samples from all three groups of dogs for $25(\mathrm{OH}) \mathrm{D}$ analysis were frozen within 1 hour of collection and stored at $-70^{\circ} \mathrm{C}$ before being sent to the laboratory for analysis on dry ice. Serum concentrations of $25(\mathrm{OH}) \mathrm{D}$ were measured and validated as described in detail elsewhere ${ }^{26-27}$. Briefly, samples were extracted using acetonitrile and applied to C18 Silica Seppaks $^{\mathrm{a}}$. Metabolites were separated by straight phase high-performance liquid chromatography ${ }^{\mathrm{b}}$ using a Hewlett-Packard Zorbax-Sil Column ${ }^{c}$ eluted with hexane:propan-2-ol:methanol (92:4:4). Serum $25(\mathrm{OH}) \mathrm{D}_{2}$ and $25(\mathrm{OH}) \mathrm{D}_{3}$ were measured separately by application to a second Zorbax$\mathrm{Sil}^{\mathrm{d}}$, column eluted with hexane:propan-2-ol (98:2) and quantified by UV absorbance at $265 \mathrm{~nm}$ (radioimmuno assay) and corrected for recovery (sensitivity $5 \mathrm{nmol} / \mathrm{L}$, intra- and inter-assay

coefficients of variation $3.0 \%$ and $4.2 \%$, respectively $)^{28}$. Results were expressed as total 25(OH)D. The Specialist Assay Laboratory $\mathrm{CSB}^{\mathrm{e}}{ }^{\mathrm{e}}$ is accredited to International Organization for Standarization (ISO) 9001:2008 and ISO 13485:2003 and participates successfully in the Vitamin D quality assurance scheme. 


\section{Statistical analyses}

Kruskall-Wallis test was performed to compare $25(\mathrm{OH}) \mathrm{D}$ serum concentrations, ages and serum albumin concentrations between all groups and a post-hoc Dunn's multiple comparison test to assess differences between the $S$. lupi-infected groups. Fisher's exact test was used to compare the appetite scores between the two spirocercosis groups and a Mann-Whitney U test for comparison of $25(\mathrm{OH}) \mathrm{D}$ concentrations and the appetite scores in each spirocercosis group. This statistical analysis was performed with a commercial software package (GraphicPad Prism $\left.5^{f}\right)$

In order to evaluate the influence of age and serum albumin concentration on serum $25(\mathrm{OH}) \mathrm{D}$ concentrations in all groups, an homogeneity of slopes analysis was performed followed by an analysis of covariance (ANCOVA). Statistica $10^{\mathrm{g}}$ was used for this statistical analysis.

Breeds, and gender and spay/neuter status were compared among the three groups using the Chi-square test (Microsoft Excel 2010 ). Body weight was evaluated for normality (Kolmogorov-Smirnov test) and statistically compared among the groups (Kruskall-Wallis test) using GraphicPad Prism 5 ${ }^{\mathrm{f}}$. A multivariable linear regression analysis was performed using an adequate commercial software package (GraphicPad Prism $5^{\mathrm{f}}$ ). All 75 dogs were combined as one dataset, and the interaction and significance of gender and spay neuter status, body weight and appetite score (independent variables) with serum 25(OH)D concentrations (dependent variable) were assessed.

A P-value of $<0.05$ was considered statistically significant in all statistical tests performed. 


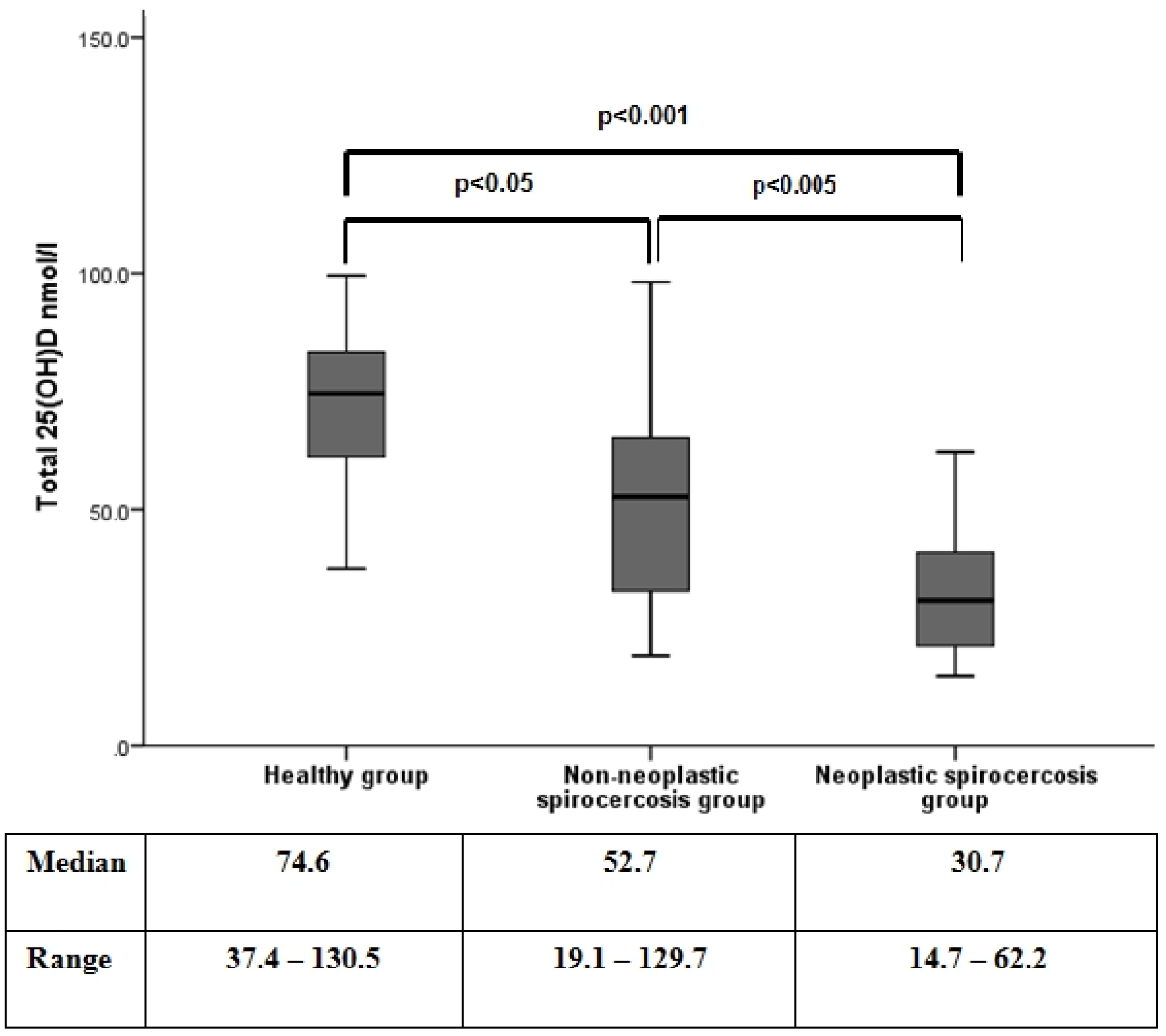

Fig. 1 - Box plot of the comparison between the serum $25(\mathrm{OH}) \mathrm{D}$ concentrations in the healthy ( $\mathrm{n}=24)$, nonneoplastic spirocercosis $(n=25)$ and neoplastic spirocercosis $(n=26)$ groups. The box incorporates the middle $50 \%$ of the observations with the line inside the box as the median. The whiskers extend to the smallest $\left(25^{\text {th }}\right.$ percentile) and largest $\left(75^{\text {th }}\right.$ percentile) observations indicating the range of the data. The median and range of serum $25(\mathrm{OH}) \mathrm{D}$ concentrations in $\mathrm{nmol} / \mathrm{l}$ are stated below the box plot. 


\section{Results}

\section{5(OH)D serum concentrations}

A statistically significant difference in serum 25(OH)D concentrations was observed between the 3 groups $(\mathrm{p}<0.001)$ (Fig. 1). Post-test analysis demonstrated that the median serum 25(OH)D concentrations were significantly lower in the neoplastic spirocercosis group [30.7 nmol/1 (range 14.7-62.2, $\mathrm{n}=26)]$ compared to the non-neoplastic spirocercosis [52.7 nmol/1 (range 19.1-129.7, $\mathrm{n}=25)(\mathrm{p}<0.05)]$ and healthy groups $[74.6 \mathrm{nmol} / 1($ range 37.4-130.5, $\mathrm{n}=24)(\mathrm{p}<0.005)]($ Fig. 1). A significant difference was also observed in the median $25(\mathrm{OH}) \mathrm{D}$ concentrations between the healthy group and the non-neoplastic spirocercosis group $(\mathrm{p}<0.05)$.

\section{Appetite scores in canine spirocercosis}

No significant differences in appetite scoring were seen between the two spirocercosis groups using the Fisher's Exact Test $(\mathrm{p}=1.0)$.

All dogs were fed a mixture of home cooked and commercial diet (various types of grocery store diets). The proportion of each diet was not possible to be determined and therefore dietary vitamin D concentrations were not quantifiable.

\section{5(OH)D serum concentrations and appetite scoring}

No significant differences were observed in the median serum $25(\mathrm{OH}) \mathrm{D}$ concentrations of dogs with normal or abnormal appetite either in the non-neoplastic spirocercosis $(p=0.125)$ (Fig. 2) or the neoplastic spirocercosis groups ( $\mathrm{p}=0.0869)$ (Fig. 3). 


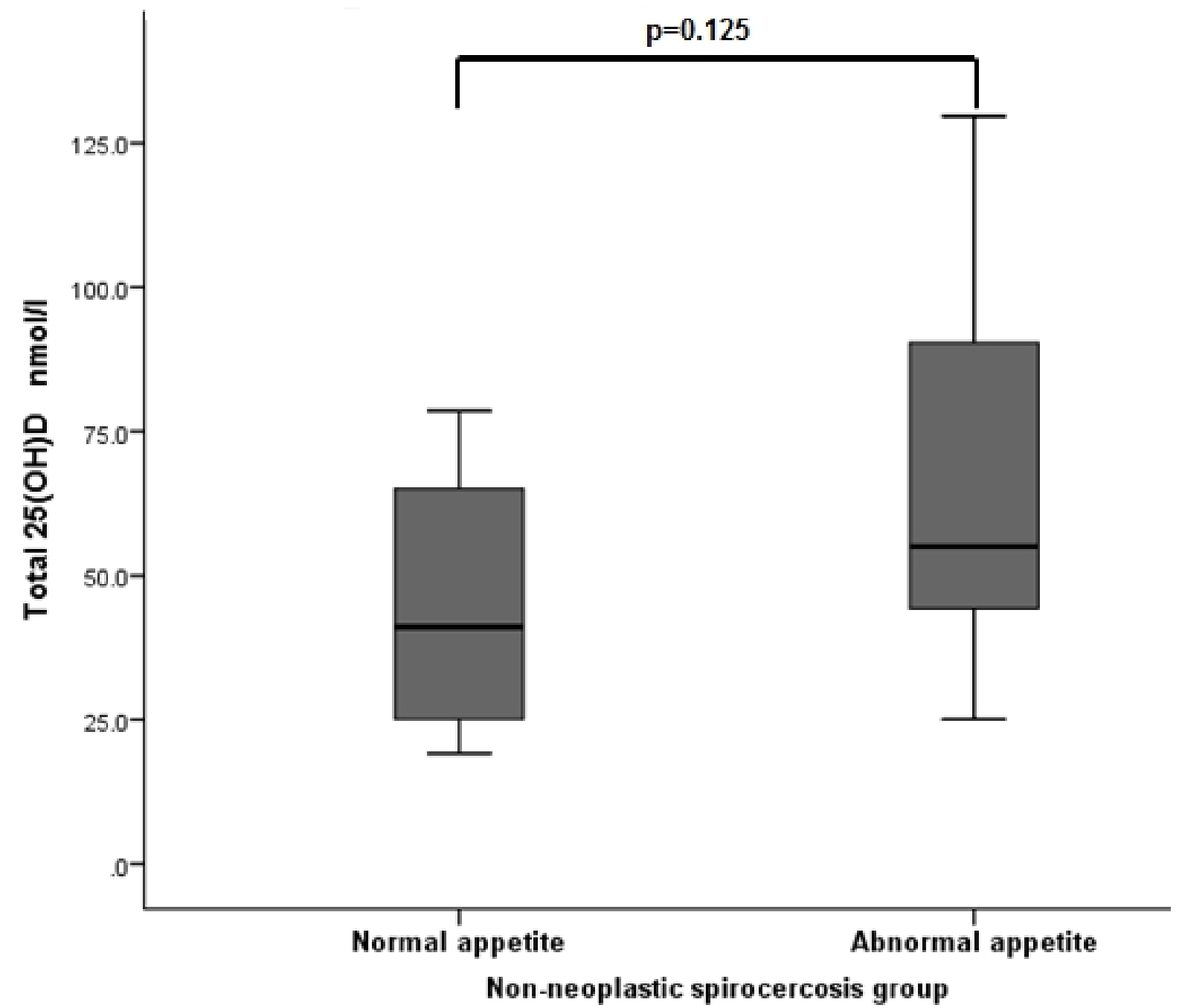

Fig. 2 - Box plot of the comparison between the median serum 25(OH)D concentrations of dogs with normal ( $\mathrm{n}=14)$ or abnormal $(\mathrm{n}=11)$ appetite in the non-neoplastic spirocercosis group $(\mathrm{p}=0.125)$ using the Mann-Whitney $\mathrm{U}$ test. The box incorporates the middle $50 \%$ of the observations with the line inside the box as the median. The whiskers extend to the smallest $\left(25^{\text {th }}\right.$ percentile) and largest $\left(75^{\text {th }}\right.$ percentile) observations indicating the range of the data. 


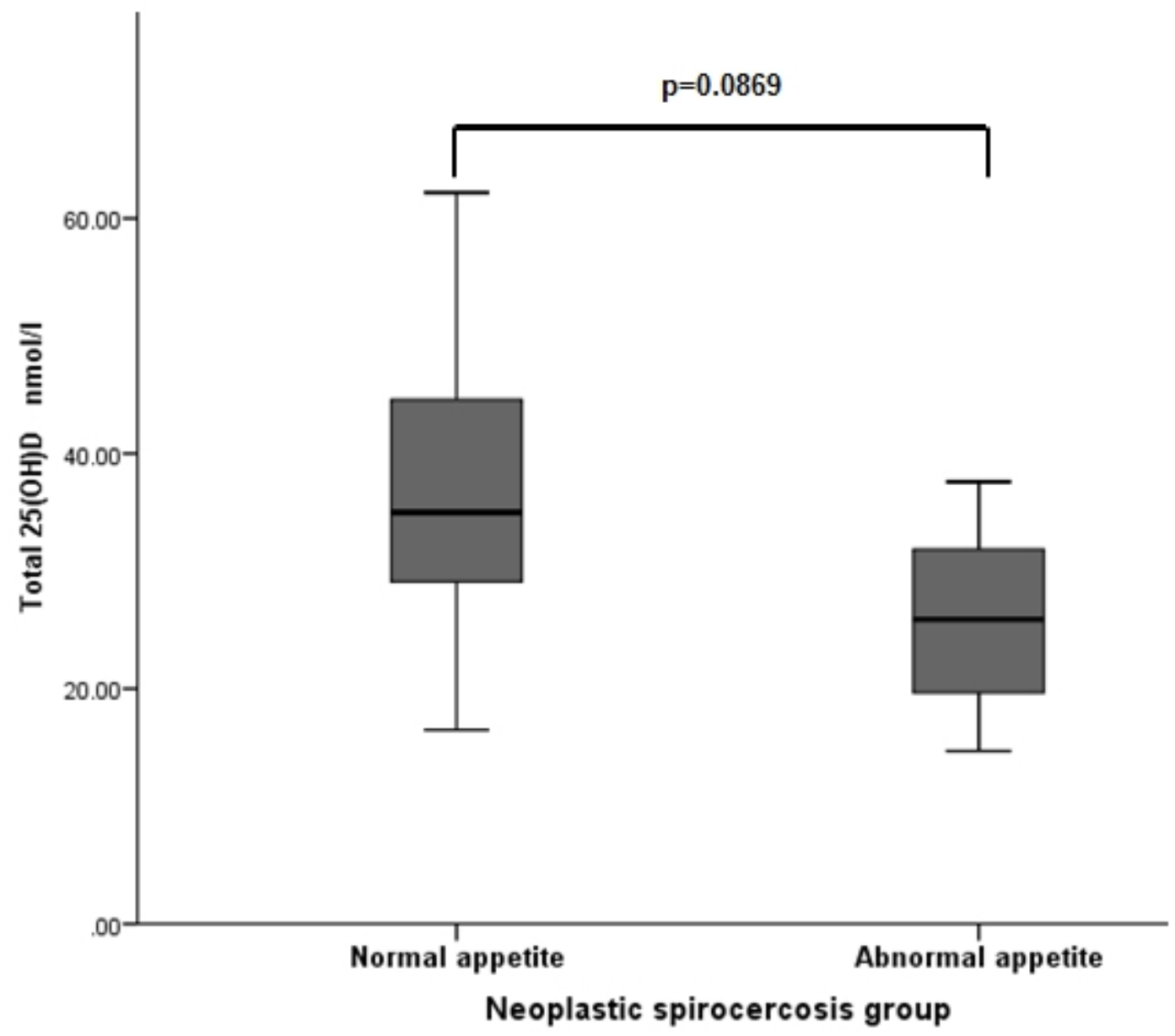

Fig. 3 - Box plot of the comparison between the median serum 25(OH)D concentrations of dogs with normal $(\mathrm{n}=15)$ or abnormal $(\mathrm{n}=11)$ appetite in the neoplastic spirocercosis group $(\mathrm{p}=0.0869)$ using the Mann-Whitney $\mathrm{U}$ test. The box incorporates the middle $50 \%$ of the observations with the line inside the box as the median. The whiskers extend to the smallest $\left(25^{\text {th }}\right.$ percentile) and largest $\left(75^{\text {th }}\right.$ percentile) observations indicating the range of the data.

Age and serum albumin concentration in canine spirocercosis and their influence on serum $25(\mathrm{OH})$ D concentrations

There was a significant difference in the ages between all groups $(\mathrm{p}<0.001)$. Post-test analysis demonstrated that the median ages were significantly higher in the neoplastic spirocercosis group [72 months (range 36-132 months, $\mathrm{n}=26$ )] compared to the non-neoplastic spirocercosis $[38.25$ months (range 16-150 months, $\mathrm{n}=25)(\mathrm{p}<0.01)]$ and healthy groups [30 months (range 12-120 
months, $n=24)(p<0.01)]$. No significant difference was observed in the median age between the healthy group and the non-neoplastic spirocercosis group $(p=1)$.

The serum albumin concentration was statistically significantly different between all groups $(\mathrm{p}<0.001)$. The median serum albumin concentration was significantly lower in the neoplastic spirocercosis group [22.1 g/1 (range 12.1-35.9, $\mathrm{n}=26)]$ compared to the non-neoplastic spirocercosis $[32.1 \mathrm{~g} / \mathrm{l}$ (range 23.1-37.4, $\mathrm{n}=25)(\mathrm{p}<0.001)]$ and the healthy groups $[35.2 \mathrm{~g} / \mathrm{l}($ range 24.5-39.2, $\mathrm{n}=24)(\mathrm{p}<0.001)]$. From the non-neoplastic spirocercosis group $5 / 25$ dogs had evidence of soft feces and 9/26 neoplastic spirocercosis dogs had diarrhea, possibly contributing to the hypoalbuminemia. No significant difference was observed in the median serum albumin concentration between the non-neoplastic spirocercosis and the healthy groups $(p>0.05)$.

The ANCOVA demonstrated a significant difference in serum $25(\mathrm{OH}) \mathrm{D}$ concentrations between the three groups of dogs that was independent of either albumin or age $(\mathrm{p}<0.05)$.

Breed, body weight, gender and spay neuter status and their influence on serum $25(\mathrm{OH}) \mathrm{D}$ concentration

No statistical significance was detected for breed $(\mathrm{p}=0.84)$, gender and spay neuter status $(\mathrm{p}=0.38)$ among the three groups (Table 1). Breeds varied within all groups (total 26 dog breeds) including small, medium, large and giant breed dogs.

The non-neoplastic spirocercosis dogs had a median body weight of $30.2 \mathrm{~kg}$ (range 6.9-78), followed by the healthy ones with $29.7 \mathrm{~kg}$ (range 5.4-70), and the neoplastic spirocercosis dogs with $23.2 \mathrm{~kg}$ (range 5.4-50) (Table 1). No statistical significant difference was observed in the median body weight among the three groups $(p=0.27)$. 
Table 1 - Body weight, gender and spay neuter status of dogs diagnosed with spirocercosis and healthy control dogs.

\begin{tabular}{|c|c|c|c|c|c|}
\hline & \multirow{2}{*}{$\begin{array}{l}\text { Median weight } \\
\text { (kg) and ranges }\end{array}$} & \multicolumn{4}{|c|}{ Gender and spay neuter status } \\
\hline & & $\begin{array}{l}\text { Intact } \\
\text { male }\end{array}$ & $\begin{array}{c}\text { Neutered } \\
\text { male }\end{array}$ & $\begin{array}{l}\text { Intact } \\
\text { female }\end{array}$ & $\begin{array}{l}\text { Neutered } \\
\text { female }\end{array}$ \\
\hline $\begin{array}{l}\text { Non-neoplastic spirocercosis } \\
\text { dogs }(n=25)\end{array}$ & $\begin{array}{c}30.2 \\
\text { (range 6.9-78) }\end{array}$ & 6 & 4 & 9 & 6 \\
\hline $\begin{array}{l}\text { Neoplastic spirocercosis dogs } \\
(n=26)\end{array}$ & $\begin{array}{c}23.2 \\
\text { (range 5.4-50) }\end{array}$ & 12 & 2 & 7 & 5 \\
\hline Healthy dogs $(n=24)$ & $\begin{array}{c}29.7 \\
\text { (range 5.4-70) }\end{array}$ & 4 & 4 & 11 & 5 \\
\hline
\end{tabular}

Multivariable linear regression analysis demonstrated that serum 25(OH)D concentration was statistically significant $(\mathrm{p}<0.001, \mathrm{r}=0.35)$, all dependent variables were independent of each other, and no linear relationship was found either with body weight $(\mathrm{p}=0.08, \mathrm{r}=0.24)$ nor appetite score $(\mathrm{p}=0.16, \mathrm{r}=-0.49)$. The gender and spay neuter status was found to negatively correlate $(\mathrm{p}<0.05, \mathrm{r}=-0.55)$ with $25(\mathrm{OH}) \mathrm{D}$ concentration, with neutered and female dogs having higher $25(\mathrm{OH}) \mathrm{D}$ concentrations than intact and male dogs.

\section{Discussion}

This study has shown that serum $25(\mathrm{OH}) \mathrm{D}$ is low in canine spirocercosis and that it is significantly lower in the neoplastic form of the disease compared to the non-neoplastic form. A reduction of serum $25(\mathrm{OH}) \mathrm{D}$ concentrations with progression of the disease from a nonneoplastic to a neoplastic state was also evident in this study. These results were independent of 
appetite, age and serum albumin and the low vitamin D status could thus potentially play a role in the neoplastic transformation of canine spirocercosis.

Causes of reduced serum $25(\mathrm{OH}) \mathrm{D}$ concentrations could be attributed to anorexia, alterations in hepatic function or over-expression of $\mathrm{FGF}_{23}$ and $24(\mathrm{OH})$ ase activity ${ }^{9,11-13}$. Firstly, our study showed that appetite was unlikely to account for the difference in serum $25(\mathrm{OH}) \mathrm{D}$ concentrations between the spirocercosis groups. However, it is possible that dogs that had inflammatory esophageal disease or neoplasia were eating less commercial dog food and more table foods that are notoriously vitamin $\mathrm{D}$ deficient than control dogs which may of contributed to the vitamin D deficiency. Secondly, only dogs without evidence of liver disease based on serum liver enzymes evaluation, abdominal ultrasonographic findings and/ or histopathology were included in the study. Therefore hepatic disease was also an unlikely cause of the reduced $25(\mathrm{OH}) \mathrm{D}$ concentrations. Thirdly, we speculate that the pathophysiologic mechanism leading to the low serum 25(OH)D concentrations in spirocercosis could relate to increased catabolism due to $\mathrm{FGF}_{23}$ over-expression and increase 24-OHase activity ${ }^{9-10,13}$, genetic mutations leading to reduced $25(\mathrm{OH}) \mathrm{D}$ synthesis ${ }^{29}$ or chronic inflammation ${ }^{16,30}$. Neoplastic and non-neoplastic spirocercosis nodules have been previously shown, to over-express FGF, with higher expressions in the neoplastic compared to the non-neoplastic $\operatorname{cases}^{31}$. This could potentially contribute to the low vitamin D status detected in spirocercosis compared to healthy dogs. Genetic mutations leading to over-expression of FGF or genetic polymorphisms in genes encoding VDR, vitamin D-binding protein, $1 \alpha(\mathrm{OH})$ ase $(C Y P 27 B 1), 24(\mathrm{OH})$ ase $(C Y P 24 A 1)$ and $25(\mathrm{OH})$ ase $(C Y P 2 R 1)$ remain possible ${ }^{29}$, although further studies to prove this association are required. Chronic inflammation caused by parasitic infections is recognized as an important risk factor for neoplastic development ${ }^{30}$. Inflammatory mediators that are produced can induce DNA damage in 
tumor suppressor genes leading to post-translational modifications of proteins involved in cellular apoptosis, DNA repair, and cell cycle checkpoints ${ }^{30,32}$. The association between neoplasia development, chronic inflammation ${ }^{32}$ and vitamin $\mathrm{D}$ has been shown in in vitro human $^{12,18,22}$ and animal $1^{22,24}$ studies, and in human epidemiologic ones ${ }^{9,12}$. Chronic inflammation leads to lipid peroxidation and potentially genetic mutations ${ }^{32}$. If these mutations accumulate in key host cell regulatory genes they can eventually change the cell phenotype and lead to neoplasia $^{32}$. Vitamin D seems to modulate the immune system preventing neoplasia by suppressing inflammation that facilitates tumorigenesis and by activating receptors of cells of the adaptive immune system in the presence of abnormal cells or antigens ${ }^{22}$. So in the presence of inflammation or neoplasia hypovitaminosis D is expected. Additionally, in a recent study induced endotoxemic dogs were found to have low serum vitamin D concentrations ${ }^{16}$. Hypovitaminosis D in sepsis results from an impaired activity of the $1 \alpha \mathrm{OHase}$, reduced DBP and loss of urinary $25(\mathrm{OH}) \mathrm{D}^{16}$. In our study the hypovitaminosis $\mathrm{D}$ in the non-neoplastic spirocercosis seems an effect of chronic inflammation, and a potential predisposing factor for the neoplastic transformation.

Reduction in serum vitamin D concentrations has been associated with increasing age ${ }^{34}$, however this study has demonstrated a trend of reduction of serum $25(\mathrm{OH}) \mathrm{D}$ concentrations with progression of the disease from non-neoplastic to neoplastic independent of age. The $25(\mathrm{OH}) \mathrm{D}$ concentrations were lower in non-neoplastic group versus the healthy group, yet the ages were similar, supporting the fact that age is unlikely to account for the differences in vitamin D. The relationship between age, vitamin $\mathrm{D}$ and neoplasia remains questionable as many exposures and events accumulate with age, potentially leading to genetic mutations and and epigenetic changes associated with neoplasia development ${ }^{22}$. 
Some of the dogs in this study had low albumin and evidences of soft feces or diarrhea. Gastrointestinal albumin loss has been shown to correlate with serum $25(\mathrm{OH}) \mathrm{D}$ concentrations in dogs with intestinal bowel disease (IBD). Intestinal loss of DBP was postulated as one of the potential causes of hypovitaminosis D in dogs with IBD and hypoalbuminemia ${ }^{17,35-37}$. In this study although the serum albumin was significantly lower in the neoplastic group, the hypovitaminosis D was independently lower, and therefore it can only be regarded as a contributing factor to the low vitamin D concentrations. This phenomenon although valid, would still not explain the hypovitaminosis D detected in the remaining dogs without evidence of diarrhea, soft feces or hypoalbuminemia. The cause of the hypoalbuminemia seen in our study could relate to loss from the ulcerated neoplastic lesion, malnutrition, parasitism or chronic inflammation (albumin is a negative acute phase protein).

The anti-neoplastic treatment properties of calcitriol leading to tumour regression have been shown in in vitro and in vivo canine neoplasias ${ }^{18-20,24}$ (transitional cell carcinomas ${ }^{18}$, mast cell

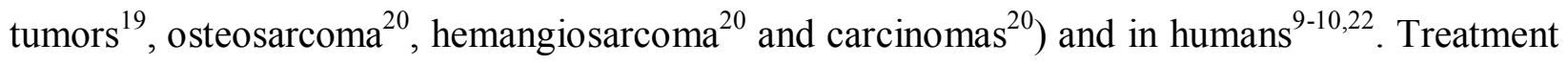
of neoplastic cells with $1,25(\mathrm{OH})_{2} \mathrm{D}$ may inhibit cell tube formation and tumour growth by repressing vascular endothelial growth factor (VEGF) and IL-8 ${ }^{10}$. Canine neoplastic spirocercosis has also shown to have over-expression of IL- $8^{38}$ and VEGF ${ }^{29}$, therefore the use of $1,25(\mathrm{OH})_{2} \mathrm{D}$ as an adjuvant therapeutic agent in the neoplastic spirocercosis could be considered. Its use in the non-neoplastic spirocercosis could also be beneficial for its anti-inflammatory effects on COX-2 expression and prostaglandin pathway $^{21}$, potentially reducing the risk of neoplastic transformation. The major in vivo limitation for calcitriol supplementation/treatment is the potential hypercalcemic effects specially when used for its anti-neoplastic effects (dosedependent effect), as high doses would be required ${ }^{19}$. Further studies are warranted in order to 
recommend calcitriol treatment and to evaluate if it would decrease the incidence of neoplastic transformation. If used, serum calcium concentrations should be closely monitored.

Limitations of this study include lack quantification of the dogs' appetite and proportion of home cooked diet versus commercial diet, and lack body condition scoring. These parameters could have been related to the vitamin D concentrations.

\section{Conclusion}

This study showed low serum $25(\mathrm{OH}) \mathrm{D}$ concentration in canine spirocercosis with lower concentrations in the neoplastic group. The hypovitaminosis D detected in the non-neoplastic spirocercosis could relate to FGF over-expression or chronic inflammation and immune system suppression, and potentially be a risk factor for the neoplastic transformation. Further studies are required to consider vitamin $\mathrm{D}$ as potential adjuvant therapeutic agent for its anti-proliferative, apoptotic and anti-angiogenic effects and to elucidate the role of vitamin D in the pathogenesis of the neoplastic transformation of canine spirocercosis.

\section{Footnotes}

${ }^{\mathrm{a} C} 18$ Silica Sep-paks, Waters Ltd, Elstree, United Kingdom

${ }^{b}$ High-performance liquid chromatography, Waters Associates, Milford, United States of America

${ }^{\mathrm{c}}$ Hewlett-Packard Zorbax-Sil Column, Hichrom, Reading, United Kingdom

dZorbax-Sil, Agilent Technologies, Stockport, United Kingdom

'Specialist Assay Laboratory CSB3, Manchester Royal Infirmary, Manchester, United Kingdom

fGraphicPad Prism 5, GraphPad Software Inc., California, United States of America 
${ }^{g}$ Statistica 10, StatSoft Inc., Oklahoma, United States of America

${ }^{\mathrm{h}}$ Microsoft Excel 2010, Microsoft, United States of America

\section{References}

1. Bailey WS. Parasites and cancer: sarcoma in dogs associated with Spirocerca lupi. Ann NY Acad Sci 1963;108:890-923.

2. Seibold HR, Bailey WS, Hoerlein BF, et al. Observations on the possible relation of malignant esophageal tumors and Spirocerca lupi lesions in the dog. Am J Vet Res 1955;16:514.

3. Ranen E, Lavy E, Aizenberg I, et al. Spirocercosis-associated esophageal sarcomas in dogs: A retrospective study of 17 cases. Vet Parasitol 2004;119:209-221.

4. Van der MerweL, Kirberger RM, Clift S, et al. Spirocerca lupi infection in the dog: A review. Vet J 2008;176:294-309.

5. Dvir E, Clift SJ, Williams MC. Proposed histological progression of the Spirocerca lupiinduced oesophageal lesion in dogs. Vet Parasitol 2012;168:71-77.

6. Dvir E, Kirberger RM, Malleczek D. Radiographic and Computed Tomographic changes and clinical presentation of Spirocercosis in the dog. Vet Radiol Ultrasound 2001;42:119-129.

7. Dvir E, Kirberger RM, Mukorera V, et al. Clinical differentiation between dogs with benign and malignant spirocercosis. Vet Parasitol 2008;155:80-88.

8. Schenck PA, Chew DJ, Nagode LA, Rosol TJ. Disorders of calcium: Hypercalcemia and hypocalcemia. In: DiBartola SP (ed). Fluid, electrolyte, and acid-base disorders in small animal practice, $3^{\text {rd }}$ ed. Missouri: Elsevier, Inc.;2006:122-194.

9. Bikle D. Nonclassic actions of vitamin D. J Clin Endocrinol Metab 2009;94:26-34. 
10. Rosen CJ, Adams JS, Bikle DD, et al. The nonskeletal effects of vitamin D: An endocrine society scientific statement. 2012;33(3):456-492.

11. Hazewinkel $\mathrm{H}$, Tryfonidou M. Vitamin $\mathrm{D}_{3}$ metabolism in dogs. Mol Cel Endocrinol 2002;197:23-33.

12. Mullin GE, Dobs A. Vitamin D and its role in cancer and immunity: A prescription for sunlight. Nutr Clin Pract 2007;22:305-322.

13. Christakos S, Ajibade D, Dhawan P, et al. Vitamin D: Metabolism. Endocrinol Metab Clin 2010;39:243-253.

14. Hostutler RA, DiBartola SP, Chew DJ, et al. Comparison of the effects of daily and intermittent-dose calcitriol on serum parathyroid hormone and ionized calcium concentrations in normal cats and cats with chronic renal failure. Vet Intern Med 2006;20:1307-1313.

15. Galler A, Tran JL, Krammer-Lukas S, et al. Blood vitamin levels in dogs with chronic kidney disease. Vet J 2012;192:226-231.

16. Holowaychuk MK, Birkenheuer AJ, Li J, et al. Hypocalcemia and hypovitaminosis D in dogs with induced endotoxemia. J Vet Intern Med 2012;26:244-251.

17. Gow AG, Else R, Evans H, et al. Hypovitaminosis D in dogs with inflammatory bowel disease and hypoalbuminemia. J Small Anim Pract 2011;52:411-418.

18. Kaewsakhorn T, Kisseberth WC, Capen CC, et al. Effects of calcitriol, seocalcitiol, and medium-chain triglyceride on a canine transitional cell carcinoma cell line. Anticancer Res 2005;25:2689-2696.

19. Malone EK, Rassnick KM, Wakshlag JJ, et al. Calcitriol (1,25-dihydroxycholecalciferol) enhances mast cell tumour chemotherapy and receptor tyrosine kinase inhibitor activity in vitro 
as single-agent activity against spontaneous occurring canine mast cell tumours. Vet Comp Onc 2010;8:209-220.

20. Rassnick KM, Muindi JR, Johnson CS, et al. In vitro and in vivo evaluation of combined calcitriol and cisplatin in dogs with spontaneous occurring tumours. Cancer Chemother Pharmacol 2008;62:881-891.

21. Krishnan AV, Trump DL, Johnson CS, Feldman D. The role of vitamin D in cancer prevention and treatment. Endocrinol Metab Clin N Am 2010;39:401-418.

22. Fleet JC, Desmet M, Johnsons R, Li Y. Vitamin D and cancer: a review of molecular mechanisms. Biochem J 2012;441:61-76.

23. Wakshlag JJ, Rassnick KM, Malone EK, et al. Cross-sectional study to investigate the association between vitamin D status and cutaneous mast cell tumours in Labrador retrievers. $\mathrm{Br}$ J Nutr 2011;106:60-63.

24. Kunakornsawat S, Rosol TJ, Capen CC, et al. Effects of $1,25(\mathrm{OH})_{2} \mathrm{D}_{3}, 25(\mathrm{OH}) \mathrm{D}_{3}$, and EB1089 on cell growth and vitamin D receptor mRNA and $1_{\alpha}$-hydroxylase mRNA expression in primary cultures of the canine prostate. J Steroid Biochem Mol Biol 2004;89-90:409-412.

25. Epstein S, Schneider AE. Drug and hormone effects on vitamin D metabolism. In: Pike JW, Glorieux FH, Feldman D (ed). Vitamin D, $2^{\text {nd }}$ ed. Oxford: Elsevier Inc.;2005:1253-1291.

26. Mawer EB, Hann JT, Berry JL, Davies JL. Vitamin D metabolism in patients intoxicated with ergocalciferol. ClinSci 1985;68:135-141.

27. Mawer EB, Berry JL, Cundall JP, et al. A sensitive radioimmunoassay using a monoclonal antibody that is equipotent for ercalcitriol and calcitriol (1,25-dihydroxy vitamin D2 and D3). Clin Chim Acta 1990;190:199-209. 
28. Berry JL, Martin J, Mawer EB. 25-Hydroxyvitamin D assay kits: speed at cost of accuracy? In: Norman AW, Bouillion R, Thomasset M (eds). Vitamin D endocrine system: Structural, biological, genetic and clinical aspects. University of California: Riverside, California;2000:797-800.

29. Kitanaka S, Isojima $\mathrm{T}$, Takaki $\mathrm{M}$, et al. Association of vitamin D-related gene polymorphisms with manifestation of vitamin D deficiency in children. Endocrinol $\mathrm{J}$ 2012;59:1007-1014.

30. Morrison WB. Inflammation and cancer: A comparative view. J Vet Intern Med 2012;26:18-31.

31. Dvir E, Clift S. Evaluation of selected growth factor expression in canine spirocercosis (Spirocerca lupi)-associated non-neoplastic nodules and sarcomas. Vet Parasitol 2010;174:257266.

32. Moss SF, Blaser MJ. Mechanisms of disease: inflammation and the origins of cancer. Nat Clin Pract Onc 2005;2:90-97.

33. Kamen DL, Tangpricha V. Vitamin D and molecular actions on the immune system: modulation of innate and autoimmunity. J Molec Med 2010;88:441-450.

34. Tuohimaa P. Vitamin D, aging, and cancer. Nutr Res 2008;66:147-152.

35. Pappa MH, Gordon CM, Saslowsky TM, et al. Vitamin D status in children and young adults with inflammatory bowel disease. Pedriatics 2006;118:1950-1961.

36. Abreu MT, Kantorovich V, Vasiliauskas EA, et al. Measurement of vitamin D levels in inflammatory bowel disease patients reveals a subset of Crohn's disease patients with elevated 1,25-dihydroxivitamin D and low bone mineral density. Gut 2004;53:1129-1136. 
37. Lo CW, Paris PW, Clemens TL, et al. Vitamin D absorption in healthy subjects and in patients with intestinal malabsorption syndromes. Am J ClinNutr1985;42:644-649.

38. Dvir E, Mellanby RJ, Kjelgaard-Hansen M, Schoeman JP. Plasma IL-8 concentrations are increased in dogs with spirocercosis. Vet Parasitol 2012;190:185-190. 